\title{
La pérdida de legitimidad de los partidos políticos argentinos Ricardo Sidicaro
}

Ricardo Sidicaro es Profesor de la Universidad de Buenos Aires e Investigador de CONICET

Mail: rsidicaro@mail.fsoc.uba.ar

\section{resumen}

Para analizar las causas de la declinación de la legitimidad de los partidos políticos argentinos en el período de reconstrucción institucional abierto en 1983, este artículo se centra: 1) en el sentido de las acciones de los dirigentes políticos y 2) en las transformaciones de las subjetividades de los ciudadanos. El análisis sostiene que en la medida que la vida política nacional de 19301983 se caracterizó por la violación casi permanente de las reglas democráticas, los dirigentes políticos adquirieron estilos de acción que luego obstaculizaron la construcción de un sistema democrático moderno. Desde 1983, en la sociedad, las combinaciones entre reclamos antimilitaristas y demandas democráticas produjeron muchas expectativas que luego se frustraron. Por otra parte, el debilitamiento de la cohesión social y la mayor libertad cultural aumentaron los niveles de exigencias políticas de los ciudadanos y sus críticas a los partidos políticos.

\section{summary}

To analyze the reasons of the decline of the legitimacy of the Argentine political parties in the period of institutional reconstruction opened in 1984, this article centres: 1) in the sense of the actions (shares) of the political leaders and 2 ) in the transformations of the subjectivities of the citizens. The analysis holds that in the measure that the political national life of 1930-1983 characterized for the almost permanent violation of the democratic rules, the political leaders acquired styles of action that complicated then the construction of a democratic modern system. From 1983, in the society, the combinations between claims antimilitarists and democratic demands produced many expectations that then frustrated. On the other hand, the weakening of the social cohesion and the major cultural freedom increased the levels of political requirements of the citizens and his critiques to the political parties.

\section{palabras claves}

partidos políticos / Estado / democracia Argentina

\section{keywords}

political parties / State / democracy Argentina 
Existen numerosos observables empíricos que permiten considerar a la pérdida de legitimidad de los partidos políticos como una de las características principales de la actual situación argentina. Ese fenómeno no es reciente, sus manifestaciones variaron en el curso de los últimos dos decenios, pero a partir de la crisis de 2001 adquirió una notable visualización pública. Abordar este tema es, por cierto, introducirse en una cuestión compleja, en buena medida oscurecida y simplificada al ser mencionada corrientemente sin mayor precisión conceptual y como parte de controversias en las pujas por posiciones de poder. No está de más recordar que los conocimientos de las ciencias sociales sobre procesos en curso suelen tener fronteras porosas o difusas con los argumentos de los actores más directamente concernidos, con las opiniones normativas de índole jurídico y con las narraciones de los medios de comunicación. Usualmente, los avatares de la política que invaden las preocupaciones ciudadanas se trivializan y son naturalizados al punto tal que se pierde su significado detrás de anécdotas sobre las idiosincrasias de los altos personajes o las atribuciones de culpas.

En términos sociológicos, la legitimidad política de un actor, individual o colectivo, se estima considerando el grado positivo de consenso social acordado a sus desempeños. En el caso de las democracias modernas, se trata, entonces, de una creencia existente en la ciudadanía situada en un plano distinto al de sus preferencias por una u otra fuerza política. A su vez, las creencias sobre los grados de legitimidad de los partidos pueden ser distintas a las referidas a la validez del orden político vigente y a la valoración de la función de los partidos, en abstracto, en tanto mecanismos necesarios para la representación de la diversidad de opiniones de la ciudadanía. En el caso argentino, como en muchos otros países, los considerables porcentajes de personas que critican los modos de acción de los partidos, no manifiestan puntos de vista adversos hacia el régimen político democrático y el principio de representación partidaria. En ese marco de percepciones de la vida pública, la erosión de la confianza en los dirigentes partidarios se combina contradictoriamente con el apoyo al sistema de regulaciones institucionales que supone necesaria su existencia para representar y para gobernar. De allí que no deba resultar paradójico que los mismos individuos inclinados a denostar a los dirigentes políticos en general, a la hora electoral escojan por algunos de sus partidos y declaren luego no tener expectativas en ser representados por ellos. En cierto sentido, puede decirse que la creencia en la validez del orden político democrático opera como un factor que da estabilidad a la democracia y neutraliza las posibilidades de que minorías activas antidemocráticas, de origen militar o civil, intenten la instauración de regímenes de tipo autoritario. Por otra parte, es probable que la distancia establecida entre la sociedad y los dirigentes partidarios haya favorecido la libertad de estos últimos para transgredir normas que, de todos modos, la ciudadanía suponía que no respetaban. En tanto las elecciones y las alternancias constituyeron elementos esenciales del orden democrático, los dirigentes de partidos cuya descomposición creciente era evidente continuaron obteniendo reconocimientos electorales y posiciones de gobierno y, en cierto grado, algunos candidatos consiguieron crear circunstancialmente una buena aceptación en parte de la sociedad, aunque 
los estudios de opinión seguían reflejando la falta de confianza de los ciudadanos en sus partidos. Las entrevistas y las encuestas que revelan la falta de confianza de la sociedad en los partidos argentinos proporcionan informaciones confiables sobre las creencias vigentes en la sociedad sobre su pérdida de legitimidad, sin ser esos los únicos observables empíricos al respecto. Hechos más puntuales tales como los estallidos de protestas sociales, las acciones de autorepresentación de las personas que suponen no tener otros medios para hacer valer sus derechos o para peticionar, el ausentismo electoral, el voto en blanco, son otros tipos de conductas que pueden leerse en la misma clave.

En este texto nos preguntaremos sobre las causas del deterioro de la legitimidad de los partidos diferenciando dos planos de análisis: 1) el de las ambivalencias iniciales del proceso de reconstrucción de las instituciones democráticas; y 2) el de las transformaciones de la sociedad que incidieron en los cambios de las creencias sobre la política. Ambos planos forman parte de una totalidad compleja de la que sólo destacaremos algunos de sus nexos más relevantes. En fin, no está de más aclarar que los procesos particulares, las corrientes de opinión, los acontecimientos puntuales o los sistemas de acciones delimitados espacio-temporalmente que mencionaremos, sólo tendrán por finalidad sustentar empíricamente nuestra interpretación sociológica.

\section{Las opiniones ciudadanas}

Para la elaboración de este análisis fueron de fundamental importancia los resultados de una investigación que realizamos en los años 2004-2005 sobre la legitimidad de las instituciones estatales y de los partidos políticos argentinos. ${ }^{1}$ Una amplia mayoría de los entrevistados coincidió en criticar a los dirigentes de los partidos políticos por considerarlos: ajenos a las demandas y necesidades de la sociedad; preocupados por preservar sus cargos y los beneficios derivados de los mismos; incumplidores de sus anuncios electorales; carentes de capacidad para la gestión pública y, mediante ideas diversas, asociaron la política con la búsqueda de oportunidades ilícitas de enriquecimiento personal. En sus sentidos clásicos y modernos, el término corrupción tuvo una recurrente presencia en los relatos recogidos. Si bien los entrevistados fueron seleccionados de acuerdo a las distintas situaciones y condiciones sociales presentes en el conjunto del cuerpo electoral, las críticas a la falta de representatividad de las dirigencias partidarias fue casi unánime. En parte, la diversidad de las inserciones en la sociedad incidió en los estilos de argumentación: quienes tenían mayores formaciones educativas o se desempeñaban en puestos jerárquicos mostraron más propensión a proponer soluciones, ese tipo de respuestas fueron menos frecuentes en el resto de los entrevistados. Con independencia de ciertas variaciones menores relacionadas con experiencias generacionales, la valoración positiva del orden político democrático y las críticas a los dirigentes de los partidos fueron el punto de convergencia de la mayoría de las opiniones recogidas.

En general, los entrevistados de más de 40 años expresaron sentimientos de desencanto al referirse a sus expectativas políticas de la época de comienzos del 
régimen democrático. Una parte de esas personas hizo menciones explícitas a las esperanzas frustradas en materia de mejora de las condiciones socioeconómicas de la población, sin ser ese el tema que predominó. Las objeciones al modus operandi de los partidos en general no establecieron mayores distinciones entre los mismos. Sólo en una cantidad numéricamente poco significativa de los entrevistados, el descontento sobre el presente era acompañado de objeciones a eventuales abandonos de tradiciones ideológicas de los partidos a los que habían votado. En cuanto a los viejos enfrentamientos que en otras circunstancias dividieron las sensibilidades políticas nacionales, su mención fue secundaria. La antinomia efectivamente recurrente fue de otro carácter: nosotros, los ciudadanos, y ellos, los dirigentes políticos. Con independencia de sus discrepancias sobre los gobiernos iniciados a partir de 1983, la mayoría de las opiniones coincidió en la condena a la dictadura militar y a sus responsables. En lo que hace a las experiencias personales, sólo alrededor de un $10 \%$ de los entrevistados dijo haber participado de las actividades de algún partido político y una proporción ínfima declaró mantener todavía algún tipo de relación. Sobre la crisis de diciembre de 2001, las referencias a los perjuicios ocasionados por el fin de la convertibilidad fueron netamente más numerosas que las evocaciones del rechazo contra los dirigentes partidarios manifestado en aquella ocasión por los sectores movilizados de la población. El fin del gobierno de De la Rúa apareció como un hecho importante sólo para los entrevistados que se mostraron más interesados por cuestiones políticas. En general, primó el pesimismo sobre las posibilidades de renovación de las dirigencias partidarias o de sus modos de acción. Sin dejar de manifestar falta de confianza en la dirigencia política, una cierta cantidad de los entrevistados reveló expectativas favorables al inicio del gobierno de Néstor Kirchner.

El análisis de las opiniones recogidas por nuestra investigación fue realizado mediante una lectura que apuntó a la comprensión global del sentido de lo dicho por los entrevistados, en tanto expresión de subjetividades individuales que con sus recuerdos no sistemáticos y sus ambigüedades, expresan pensamientos colectivamente compartidos sobre situaciones vividas individualmente pero decodificadas desde puntos de vista, o de visión, condicionados por los lugares ocupados en el espacio social. Digamos que si en apariencia no hay nada que se pueda considerar más personal que el acto de contestar en una entrevista, comparable si se quiere al de entrar al cuarto oscuro a depositar un sufragio, las selecciones de los recuerdos y de las palabras, al igual que las de los candidatos que se a vota, están socialmente condicionadas y expresan un saber común y experiencias colectivas y, casi siempre, previamente habladas. La alta homogeneidad de las miradas críticas sobre los dirigentes partidarios, más allá de las evaluaciones puntuales no necesariamente concordantes, brindó ejes temáticos, no siempre nombrados explícitamente por los entrevistados, a partir de los cuales nos propusimos establecer la comprensión del sentido de las conductas de quienes estiman que, por acción u omisión, los partidos y sus dirigentes carecen de legitimidad.

Además de los datos cualitativos de nuestra investigación, hemos empleado informaciones elaboradas por distintas entidades que realizan mediciones cuantitati- 
vas periódicas de los niveles de confianza en las instituciones públicas. En el Cuadro 1 se resumen los resultados de un estudio realizado por la consultora Gallup:

\section{Cuadro 1. Indicadores de confianza en las instituciones 1984-2007}

\begin{tabular}{|c|c|c|c|c|}
\hline & 1984 & 1991 & 2002 & 2007 \\
\hline Congreso & $73 \%$ & $17 \%$ & $7 \%$ & $12 \%$ \\
\hline Partidos Políticos & $(* *)$ & $15 \%$ & $4 \%$ & $7 \%$ \\
\hline
\end{tabular}

Fuente: Estudio acerca del trabajo voluntario y la responsabilidad empresaria. Gallup Argentina 2007

Cabe señalar que en la fuente citada se aclara que la primera medición sobre la confianza en los partidos políticos fue hecha en 1987 y que en esa oportunidad el $38 \%$ de los encuestados manifestó confiar en ellos. Después de 1984, el aumento del porcentaje de opiniones críticas sobre el Congreso, es el indicador que mejor resume la caída de las expectativas puestas por la ciudadanía en la nueva etapa de la vida política nacional. Es interesante señalar que la leve recuperación de los porcentajes de confianza en el Congreso y en los partidos registrada entre 2002 y 2007, no alteraron significativamente la tendencia general imperante.

Cuadro 2. Indicadores de déficit de confianza en las instituciones 2004-2007

\begin{tabular}{|l|l|l|}
\hline & 2004 & 2007 \\
\hline Valoración del Gobierno Nacional & $82 \%$ & $70 \%$ \\
\hline Valoración del Congreso & $94 \%$ & $84 \%$ \\
\hline Valoración de los Partidos Políticos & $98 \%$ & $95 \%$ \\
\hline Valoración del acto de votar & $14 \%$ & $22 \%$ \\
\hline
\end{tabular}

Fuente: Índice de desarrollo humano y social. Boletín del Observatorio de la deuda social argentina. $N^{\circ} 1 / 2008$. Universidad Católica Argentina ${ }^{2}$

La otra fuente a la que hemos recurrido, el Observatorio de la deuda social argentina de la Universidad Católica Argentina, corresponde a los años 2004 y 2007, y aporta datos igualmente significativos. Los indicadores sobre el Congreso y los partidos son casi similares a los del estudio de Gallup, si bien en su presentación el Observatorio opta por referirse al déficit de confianza, es decir a los porcentajes de respuestas que dicen no tener confianza. La información del Cuadro 2 muestra que entre 2004 y 2007 se registró una mínima baja porcentual en el indicador de desconfianza en los partidos, pero que mejoró de un modo relativamente mayor la 
confianza en el gobierno nacional y en el Congreso, así como la valoración asignada al acto de votar.

La buena recepción en la opinión pública de la gestión presidencial de Néstor Kirchner fue, sin duda, la razón por la que se mejoraron los porcentajes de confianza, entre 2004 y 2007, en el Gobierno nacional. Cabe destacar que la modificación positiva de los valores de dicho indicador se dio en una situación en la que a los efectos de continuar con la reconstrucción de la economía la acción gubernamental adquirió una centralidad mayor y los logros, en ese aspecto, debieron estar en la base del cierto aumento de confianza captado en las encuestas. También el Poder Ejecutivo tuvo desempeños visualizados como antimilitaristas y favorables a la política de derechos humanos que, como veremos más adelante, son cuestiones que despiertan la adhesión de una parte de la ciudadanía. En cambio, distintos análisis muestran que en ese período se registraron numerosas transgresiones al normal funcionamiento de la división de poderes, acrecentándose el decisionismo presidencial que emprendió tareas de orden legislativo constitucionalmente reservadas al parlamento. ${ }^{3}$ Aún así, los porcentajes de mejora de la confianza en el Poder Legislativo se vieron acrecentados, probablemente, por su participación en las decisiones sobre los cambios en la Corte Suprema de Justicia o en la reapertura de los juzgamientos a los responsables de delitos durante la dictadura. Es interesante señalar que lo sucedido con la confianza en el Gobierno nacional y en el Congreso, prácticamente no repercutió en la mejoría de la valoración de los partidos. Más aún, tal como veremos, en las elecciones nacionales 2007 los partidos dejaron su lugar a frentes electorales y a candidaturas personalizadas, lo que de hecho mostró un nivel alto de autoconciencia de su desprestigio.

\section{La política y la segunda modernidad}

Entre los rasgos más característicos de la actual época de la modernidad occidental se encuentra el debilitamiento del atractivo de los partidos políticos que, con manifestaciones disímiles, se registra en las más diversas sociedades de nuestros días. Es común observar como la política dejó de proveer identidades colectivas y de polarizar las opiniones de los ciudadanos.

Con conceptos durkhemnianos, puede decirse que el interés que suscitaban los partidos fue tanto mayor cuando existían tejidos sociales más integrados que daban lugar a las confrontaciones de ideas divididas en torno a las orientaciones de los llamados "destinos colectivos". En ese tipo de situaciones, los partidos fueron los actores que condensaron la expresión de las representaciones colectivas de los diferentes sectores sociales que se cristalizaron en grandes y durables clivajes políticos. Los discursos y las acciones de esos partidos crearon tradiciones políticas e ideológicas que no necesariamente han desaparecido, pero junto con la declinación de los niveles de integración social perdieron intensidad las anteriores pasiones y certezas políticas. Los vínculos sociales más laxos se reflejan en la aparición de subjetividades menos apegadas a las herencias culturales de toda índole. Si bien esos cambios no impiden que los encargados de la puesta en escena de la acción política recurran a las retóricas que otrora habían mostrado ser efectivas para mo- 
vilizar adhesiones, esos anacronismos en algunos casos debieron incrementar la desconfianza ciudadana.

Es notorio que en la medida que se diversificaron las formas actuales de vida y se modificaron las inserciones sociales rígidas y permanentes, en especial, pero no sólo, en el mundo del trabajo, se fueron produciendo vaciamientos de sentido en los contenidos de los discursos y simbologías políticas. Los viejos sistemas de alteridades colectivas que alcanzaron su apogeo en las luchas por la "ciudadanía política" primero y después por la "ciudadanía social", comenzaron luego a desdibujarse con los efectos socialmente integradores de aquellas importantes conquistas.

Luego, junto con las ampliaciones de los horizontes de posibilidades individuales, las preferencias políticas adquirieron más matices, y aún quienes siguieron votando por los mismos partidos ya no se subordinaron de igual forma a sus dirigentes y comenzaron a dudar sobre cómo orientar sus sufragios.

Con la globalización y el paso de la modernidad sólida a la modernidad líquida, para decirlo con términos de Zygmunt Bauman (2003a), no debe verse como algo paradójico que los beneficiados de los cambios políticos y sociales de la etapa sólida, relativizaron sus anteriores identificaciones políticas. Por otra parte, con el avance de las desigualdades sociales y la fragmentación de los antiguos colectivos sociales, en el pasaje de la sociedad de protección a la de inseguridad social, según las nociones propuestas por Robert Castel (2004), los individuos quedaron más expuestos a riesgos antes controlados. En procesos sociales, que como sostiene Bauman (2003b:23): "los riesgos y las contradicciones siguen siendo producidos socialmente, y se está cargando al individuo con la responsabilidad y la necesidad de enfrentarlos", hasta puede resultar un contrasentido que muchísimas personas carentes de otros medios para expresar sus situaciones de deterioro tomen distancia de los sistemas de partidos en los que podrían intentar buscar, u organizar, la representación de sus intereses.

Sin embargo, los efectos ambiguos de las transformaciones en curso no aceptan lecturas unilineales: en la nueva etapa de la modernidad occidental se producen fenómenos múltiples cuya fluidez no es inteligible empleando las herramientas conceptuales aptas para épocas precedentes. La coexistencia entre la declinación del poder de las tradiciones en las diversas esferas de la vida, con el consiguiente retroceso de las estructuras estructurantes de los modos de hacer, pensar y sentir, tanto en los dominios de lo privado como de lo público, favorecen la autonomía de la reflexividad individual y colectiva que reclama más y mejores fundadas razones para aceptar la autoridad y la legitimidad de las instancias de poder. Cuando mucho de lo sólido parece desvanecerse en el aire, los espacios nacionales-estatales y los actores vernáculos de las luchas políticas, no quedaron al margen de las crisis de confianza.

Puede afirmarse que el capital globalizado operó revolucionando las relaciones económicas y sociales y su movilidad mundial desarticuló el triángulo fordista o socialdemócrata de relaciones Estado-asalariados-empresarios. La disminución de las capacidades estatales ante los agentes del capitalismo globalizado y los orga- 
nismos internacionales de supervisión y de crédito, le restó sentido en los foros políticos a las discusiones sobre las estrategias de desarrollo autónomo y en esas circunstancias el denominado pensamiento único del neoliberalismo se convirtió en una especie de acta notarial de la constatación de la nueva situación nacional y mundial. Por su parte, la globalización cultural contribuyó a la heterogeneidad de todos los sectores sociales. En el extremo, puede afirmarse que los partidos sin ideas no fueron más que una especie de sinceramiento del hecho de la exterioridad del poder de decisión sobre los grandes asuntos públicos que tendía a restringir las intervenciones efectivas de los partidos y de los gobiernos.

Lo que Ralf Dahrendorf (1989) denominó la cuadratura del círculo o, si se prefiere, la difícil tarea de combinar el mantenimiento de la capacidad competitiva de un país bajo las inestables y agresivas condiciones de la mundialización económica, lograr ese objetivo sin lesionar las bases de la cohesión y de la solidaridad social, asegurando la plena vigencia del régimen político democrático y respetando las regulaciones de una sociedad libre, fue, sin duda, la mejor síntesis de los desafíos de la complicada situación de la política en la segunda modernidad. Los dirigentes partidarios o gubernamentales que debieron enfrentar esa situación, a diferencia de Dahrendorf no estaban en una cálida biblioteca del St. Antony's College de Oxford; se hallaban, por el contrario, al frente de naciones, estructuras partidarias o de aparatos estatales que habían entrado en la vorágine de lo que Anthony Giddens llamó un mundo desbocado. Dicho autor designó como la paradoja de la democracia, al hecho que ese tipo de régimen político "se expande por el mundo mientras que en las democracias maduras a las que el resto del mundo debe -en teoría- copiar, existe una desilusión generalizada con los procesos democráticos. En la mayoría de los países occidentales los niveles de confianza en los políticos ha caído en los últimos años. Vota menos gente que antes, particularmente en Estados Unidos. Cada vez son más quienes dicen no tener interés en la política parlamentaria, especialmente entre las generaciones jóvenes" (Giddens, 2000:85).

Con Giddens puede decirse que la modernización de los partidos fue considerablemente más lenta que los cambios registrados en los modos de vida de sus electores. En el heterogéneo panorama ideológico derivado de las modificaciones de la sociedad del último cuarto del siglo XX no faltaron, tampoco, quienes reaccionaron en defensa de los valores del "hombre y de la mujer corriente" y encontraron ecos en los discursos antipolíticos de los viejos y nuevos qualunquistas, críticos de lo que denominaban las "partidocracias".

Si la idea de la corrupción, con sus usos varios y equívocos, conoció a finales del siglo XX una enorme difusión para vilipendiar a los dirigentes partidarios o gubernamentales, fue, en buena medida, por haber canalizado malestares sociales de orígenes diversos. Desde ópticas distintas, fue el lugar común de reflexiones profanas y de reformadores éticos, que predicaban nuevas morales políticas. Aquí también cabe coincidir con Giddens y dudar sobre la novedad de la corrupción en los países democráticos, y pensar que "en una sociedad abierta a la información es más visible y los límites de lo que se considera corrupción han cambiado" 
(Ibídem, 83). Esa observación sobre los países democráticos de más larga data, probablemente no corresponde a los que combinaron la salida de regímenes de tipo totalitario o autoritario con las privatizaciones de empresas estatales, que, como lo mostraron diversos estudios, expandieron las posibilidades de corrupción partidaria y gubernamental. ${ }^{4}$

Manteniéndonos en el tema de la relación entre partidos y valores éticos, digamos que la denominada crisis del militantismo, con la disminución del componente vocacional de la acción política, favoreció la entrada en los partidos de buscadores de prebendas, centrados en los intercambios y en las gratificaciones materiales, prácticas que encuentran climas propicios en las condiciones sociales de anomia o de crisis de sentido, propias de las épocas de cambio político. Sin ser el único factor en presencia, el rechazo a la política sin valores incrementó la desconfianza de la sociedad en los partidos. Pero, como lo destaca Klaus von Beyme (1995:195), esas críticas al cinismo de los partidos no son sólo disfuncionales para el funcionamiento de los sistemas políticos ya que incentivan a sectores de sus dirigencias a buscar soluciones para superar esas imágenes negativas.

En fin, al igual que cualquier otra cuestión vinculada con cambios políticos, sociales y culturales actuales, el tema de la relación de la sociedad con los partidos deja abierto los interrogantes acerca de su carácter de fenómeno coyuntural o estructural. ¿Se trata de una distancia crítica pasajera destinada a resolverse mediante la readecuación de los partidos a las nuevas configuraciones societales o se está frente a un cambio en los vínculos de la ciudadanía con los partidos que anuncia el inicio de una modificación permanente de los modos de representación? En todo caso, una respuesta que considere, a la vez, la existencia en las sociedades occidentales de una nueva cultura política, en la que la desconfianza ciudadana frente al poder y a las jerarquías se articula con demandas mucho más individualizadas que las de épocas inmediatamente precedentes, puede permitir indagar mejor sobre las realidades presentes y evitar profecías sin fundamentos. En todo caso, está casi de más aclarar que la constatación de la declinación de la legitimidad de los partidos en muchos contextos nacionales contemporáneos, no permite explicar la existencia de esos procesos diciendo, simplemente, que esto ocurre porque es un fenómeno época.

\section{Democracia y antimilitarismo}

Juan Linz sostuvo que los gobiernos democráticos que llegan al poder sin rupturas violentas o sin enfrentamientos con los regímenes autoritarios anteriores encuentran siempre dificultades para emprender las tareas de depuración política, de modificación legislativa o de cambios de los equipos administrativos y militares (Linz, 1978:35). En el caso argentino, al listado de dificultades de Linz cabe agregar las aportadas por los dirigentes partidarios que nunca habían participado de cuerpos institucionales de deliberaciones democráticas normales durante períodos razonablemente prolongados. Tampoco los partidos políticos habían tenido vidas internas capaces de funcionar, como se suele decir, como escuelas de democracia. En las condiciones de restricciones de las libertades públicas, los microcosmos 
partidarios fueron lugares de formación de pequeños grupos que rememoraban pasados mejores que, salvo en ocasiones excepcionales, no participaban realmente en conflictos políticos.

Durante el Proceso, algunos dirigentes partidarios colaboraron con los dictadores, mientras la mayoría hibernó a la espera de su desgaste y sólo unos pocos actuaron pidiendo reivindicaciones democráticas. En las elecciones de 1983, los clivajes políticos de las épocas anteriores no se reavivaron excesivamente ya que las coincidencias pidiendo el fin del régimen autoritario operaron disminuyendo la mención de los anteriores antagonismos, pero, de todos modos, tanto los peronistas como los radicales atrajeron adhesiones por sus respectivos pasados. Probablemente, al denunciar la existencia de un pacto militar-sindical, Raúl Alfonsín consiguió ganar a su favor las sensibilidades más marcadamente antimilitaristas a la vez que estableció un nexo con la antinomia histórica. ${ }^{5}$ Los peronistas, en cambio, se mostraron más inclinados a recordar su decenio fundacional ya que el efímero gobierno 1973-76 no debió parecerles un tema proselitista atractivo y, convencidos del seguro triunfo de su candidato, prefirieron no agitar propuestas antimilitaristas. En la confusión reinante, ninguna fuerza política pareció estar en condiciones de captar las transformaciones de la sociedad y del Estado dejadas por la experiencia autoritaria que se cerraba.

En la sociedad, la efervescencia política que estalló en la agonía del régimen procesista generó una sensibilidad social antimilitarista de características desconocidas en el país, originada más por la derrota en la guerra de las Malvinas, que por las informaciones, escasas todavía, de lo sucedido en materia de violaciones a los derechos humanos. La simpatía popular que despertó en sus comienzos la iniciativa bélica del Atlántico sur actuó como un factor de reconstrucción circunstancial del tejido social. Las multitudes que plebiscitaron en las calles el inicio y desarrollo de la guerra, fueron acompañadas por la mayoría de los dirigentes de todos los partidos políticos, de las corporaciones empresarias y sindicales, y por figuras relevantes de la cultura. Esa efervescencia social cambió de signo ante la certeza de la derrota y se convirtió en la base de un verdadero sentido común antimilitar que resultó decisivo en la transformación institucional del país. Si bien en sus comienzos el conflicto malvinense había suscitado reacciones antiimperialistas que objetivamente fortalecieron a los altos jefes castrenses en la lucha contra la alteridad británica, haciéndoles fantasear, seguramente, con el logro de un duradero apoyo de masas, con la capitulación la sociedad civil buscó, esta vez sin metáfora, a los "mariscales de la derrota" y los militares in toto fueron condenados por la opinión pública. No es arriesgado suponer que sin esa indignación ciudadana, los dirigentes de los principales partidos no hubiesen optado por juzgar a las Juntas.

El antimilitarismo convertido en adhesión a la democracia, y la reconstrucción del pluralismo político pensada como lo inverso de la dictadura, formaron la base de un complicado entramado ideológico que generó las expectativas políticas y emocionales de un amplio sector de la población que por razones diversas luego se sentiría defraudado por los modos en que las dirigencias partidarias respondieron a 
sus demandas y reclamos. Esa confusión entre el antimilitarismo y la democracia fue, desde 1984, incentivada por los conflictos institucionales con el militarismo residual de esa década. Las amenazas de retorno de los militares a la escena política, así como los retrocesos en materia de castigos a los responsables del Proceso, potenciaron la particular manera en que se había definido la democracia. Puede afirmarse que en la efervescencia política del '83, se yuxtapusieron, sin coincidir, dos demandas en sentido estricto no coincidentes: la primera era la consecuencia real del desenlace de la guerra; la segunda, una expectativa imaginada sobre la democracia, cuestión ideal sobre la que la gran mayoría de la población carecía de experiencia.

Más allá del valor histórico que suele asignarse a las legislaciones de la década de 1910 sobre la instauración del sufragio universal, secreto y obligatorio, ese buen comienzo quedó archivado en menos de dos decenios. Luego, durante algo más de medio siglo las reglas democráticas de funcionamiento del sistema político fueron sistemáticamente vulneradas. Los gobiernos civiles y militares, desde 1930, restringieron, de diferentes modos y con disímiles argumentos, la plena vigencia de las libertades públicas y limitaron el pluralismo político. Al respecto, redunda nombrar aspectos emblemáticos: los conservadores de 1930/43 y el fraude; los peronistas de 1946/55 y el cercenamiento de la libre expresión; los gobiernos militares de los años 1955/73 y la anulación del pluralismo partidario; los peronistas de 1973/76 y el uso de medios extralegales de represión; el "proceso" y la supresión total del Estado de Derecho y los crímenes de lesa humanidad. En los intersticios de esos cinco decenios existieron intentos precarios de restauración democrática, sin legitimidad de origen, bajo tutela militar y en todos los casos cerrados por golpes castrenses.

Durante ese prolongado período de intervenciones de los uniformados en la vida política, importantes sectores de la sociedad civil, no siempre los mismos, participaron de la formación de coaliciones golpistas y apoyaron las políticas de los gobiernos de facto (Sidicaro, 2004). En ese medio siglo, limitaciones de los derechos de ciudadanía política fue el rasgo predominante del desarrollo institucional. El campo político sui generis creado en esa situación naturalizó tanto la presencia del actor militar destituyendo gobiernos civiles, como a los dirigentes políticos que aceptaban o prohijaban la violación de las normas constitucionales.

La ruptura histórica de 1983, no pudo, obviamente, suprimir los habitus o sistemas de predisposiciones de las dirigencias partidarias socializadas en la anormalidad institucional reinante durante un período tan prolongado. En general, los análisis que abordaron la transición argentina a la democracia no adjudicaron mayor importancia al hecho de que los partidos que debían asumir un papel central en el nuevo régimen político eran portadores de continuidades de prácticas y de modos de pensar que poco tenían en común con las virtudes republicanas necesarias para construir una democracia de tipo occidental. Los principales partidos capitalizaban sufragios de importantes conjuntos de ciudadanos con su capacidad de evocar recuerdos más o menos difusos que dividían a la sociedad en sensibilidades políticas divergentes, cuyo poder emocional se mantenía, en buena medida, ayudado 
por las discontinuidades del sistema institucional. Como un efecto no buscado de los golpes militares y las periódicas supresiones de las actividades de esos partidos, se congelaban las representaciones imaginarias de la sociedad y los discursos partidarios. Las transformaciones sociales y culturales de la sociedad alcanzaban en cierto modo a los partidos pero sus efectos se iban depositando como capas geológicas, modificando poco sus tradiciones ideológicas, sin alterar los estilos caudillistas de liderazgos.

Esas máquinas partidarias defectuosas, aisladas de la ciudadanía durante las dictaduras, en un momento u otro habían fracasado en efímeros pasos por los gobiernos. El peronismo, la fuerza política que concitaba más apoyos desde mediados de los años '40, nunca había tenido una organización normal de partido político; proscripto durante muchos años, existió como una combinación de grupos heterogéneos conducidos por un líder carismático, quien al fallecer en el gobierno sin que se hubiese producido el tipo de proceso que Max Weber denomina de rutinización del carisma, su sucesión llevó al desorden de sus seguidores. La Unión Cívica Radical conoció desde 1930 una serie de divisiones que debilitaron su capacidad electoral; su poder de convocatoria política desde mediados de los ' 40 se basó en presentarse como el rival del peronismo. Luego, la dictadura procesista les dejó a los gobernantes radicales una desorganización del Estado, de la sociedad y de la economía, que conformaron problemas cualitativamente distintos a los previstos por su dirigencia partidaria. Pero, sobre todo, el radicalismo alfonsinista había llegado al gobierno en la época de la cuadratura del círculo.

\section{La inflexión pascual}

Los sucesos de abril de 1987 no inauguraron el distanciamiento de la sociedad civil con respecto a los partidos políticos, pero dieron un salto en ese sentido, por eso perduraron en la memoria colectiva como el final de la primera etapa del período de reconstrucción de las instituciones. Semana Santa del '87 fue, si se quiere, el último acto de la efervescencia popular iniciada con la derrota en la guerra de las Malvinas. Si en el primer trienio alfonsinista, el entusiasmo por la clausura del ciclo militar se combinó con la ilusión democrática, resumidos ambos en la fuerza simbólica de los Juicios a las Juntas, las evidencias de los retrocesos ante las imposiciones de los uniformados en abril de 1987, crearon en el espíritu público las certezas de que las instancias representativas no expresaban las demandas de justicia. Los sentimientos y las expectativas antimilitaristas habían tenido ya algunos motivos de fricciones con el gobierno, pero recién con el golpe pascual pareció quedar por primera vez en claro que en las condiciones de democracia representativa el pueblo no deliberaba ni gobernaba sino por medio de sus representantes. Sin embargo, para que tal división del trabajo político, normal en los regímenes democráticos, fuese aceptada como tal por los representados hubiese sido necesario que los representantes previamente transmitiesen mediante discursos públicos y acciones partidarias ideas al respecto para hacerlas aceptar por la ciudadanía. Es probable que esa meta hubiese sido factible ya que en una demostración de confianza, según se calcula, alrededor de tres millones y medio de personas se habían 
afiliado a los dos grandes partidos tradicionales en las vísperas de las elecciones presidenciales. Sin embargo, los dirigentes de esos partidos demostraron no tener vocación, o interés, en discutir sobre el sentido de la democracia con la ciudadanía $\mathrm{o}$, al menos, en generar espacios de deliberación y formación de quienes poseían más vocación y conocimientos acerca de las cuestiones públicas.

La efervescencia política que había acompañado el establecimiento de la democracia no había sido considerada por amplios sectores de la población como un acto de delegación sin condiciones y, en especial, buena parte de aquellos que habían apoyado al radicalismo en 1983 y muchos de los que luego le dieron su adhesión por sus iniciativas tendientes a castigar a los responsables de la dictadura, no tenían subordinación a ningún partido político.

$\mathrm{Si}$ en condiciones normales los dirigentes partidarios creen que "la política es el arte de lo posible" y sus apoyos les dejan la responsabilidad de gobernar sin otro recurso que el de castigarlos en las urnas venideras, algo muy distinto sucedió cuando las movilizaciones sociales se convirtieron en actores de la esfera pública de la política en los momentos liminares de la restauración democrática. Con independencia de las cantidades de personas que participaron en las movilizaciones antidictatoriales, en la sociedad había ganado espacio un nivel de deliberación y de politización como nunca se había conocido hasta entonces: las prioridades en materia de derechos humanos y peticiones de justicia se habían colocado por encima de las comparativamente menos atractivas agendas de los partidos tradicionales. Dichos partidos, sin experiencia de gestión, se vieron superados por el lenguaje de las reivindicaciones de carácter universal que venían de la sociedad y por el tenor de los reclamos fundados en valores. Sin proponérselo, los sublevados de Semana Santa de 1987 pusieron la piedra fundacional de un nuevo período: la clásica disyuntiva entre la ética de las convicciones y la ética de las responsabilidades no fue el dilema de un actor sino que abrió dos senderos que se bifurcaron. Con la inflexión pascual, lo que dio en llamarse el posibilismo argumentó en nombre del grado de justicia posible en las condiciones políticas imperantes, mientras que en amplios sectores de la opinión movilizada se instaló la tesis de que la justicia no era materia de negociación. ${ }^{6}$

\section{La legitimidad de la democracia}

Con conceptos de Max Weber se puede caracterizar al régimen democrático como un sistema de dominación legítimo basado en la creencia reinante en la población acerca de la aceptación de las directivas y orientaciones de las autoridades políticas a cargo de la conducción de los asuntos públicos por medio de las actividades de las burocracias estatales (Weber, 1999:173-180). ${ }^{7}$ Dos elementos son fundamentales para asegurar esa creencia: el origen de las autoridades se ajusta a las normas legales establecidas para su designación y en el ejercicio de sus funciones éstas se subordinan al mandato de las leyes y aseguran la igualdad legal de los ciudadanos. No pocas veces se ha señalado el carácter formal de dicha igualdad ante la ley, pues las desigualdades sociales y económicas colocan a los individuos en asimetrías reales que contrastan con la igualdad legal. En ese sentido, la exis- 
tencia del régimen democrático debe considerarse, justamente, a partir del poder simbólico del criterio de igualdad ante la ley compartido por sujetos conscientes de vivir en sociedades social y económicamente desiguales. Los privilegios de quienes poseen más riqueza y las asimetrías cotidianas surgidas de la división del trabajo social son aspectos normales de las sociedades capitalistas cuyos sistemas políticos se rigen por principios democráticos y esas diferencias usualmente son aceptadas salvo en las situaciones de extrema injusticia. Resulta aún más interesante el hecho de que cualquier ciudadano medianamente informado sabe que sus representantes en el ejecutivo o en el parlamento, a los que otorga su sufragio, reciben desde el momento de asumir sus funciones salarios que los sitúan en el estrato correspondiente al diez por ciento superior de los perceptores de ingresos.

En las opiniones recogidas en nuestra investigación sobre la legitimidad de las instituciones públicas y de los partidos políticos argentinos, y lo mismo se constata en muchos estudios sobre temas conexos, las críticas a los dirigentes partidarios y a los funcionarios estatales en general se referían con gran frecuencia a las prácticas de corrupción y a su impunidad. Desde comienzos del decenio de 1990, las denuncias de corrupción se habían multiplicado en los medios de comunicación, encontrando acogida en las oposiciones antimenemistas, y sus ecos, naturalmente, se reflejaron en los estudios de opinión. Pero, detrás de las reiteradas menciones a la corrupción, aún cuando no todos los que nombran el tema lo digan explícitamente, se encuentra, en realidad, una cuestión mucho más significativa que el hecho de lucrar desde puestos de gobierno: la impunidad de los actos de corrupción en un régimen democrático revela la existencia de comportamientos que no se ciñen a las obligaciones de respeto a las leyes a la vez que muestran la falta de igualdad entre los ciudadanos. Si con la idea de la falta de justicia con respecto a los crímenes de la dictadura se había iniciado la erosión de la legitimidad de los dirigentes partidarios, luego, con el tema de la corrupción ese deterioro se amplió. Las percepciones individuales y/o colectivas de incumplimiento de las obligaciones legales minaron las bases del reconocimiento de las autoridades públicas y fueron haciendo crecientemente verosímiles las denuncias sobre nuevos actos de corrupción. Aún cuando, la corrupción no es una práctica inmediatamente visible, sin embargo, cuando se instala en una sociedad la creencia en su existencia a partir de algunos hechos puntuales, se deteriora la legitimidad del poder político que acepta, por acción u omisión, su existencia. ${ }^{8}$

\section{Fragmentación social y la legitimidad política}

La idea de fragmentación social se ha incorporado al uso corriente para aludir al debilitamiento de la cohesión social, o de la integración social, y al aumento de las conductas individualistas. De modo más o menos directo según los casos, la fisura social resumida en la ampliación de la brecha de ingresos entre ganadores y perdedores de la experiencia económica neoliberal suele ser la referencia más conocida de las interpretaciones sobre los cambios sociales de las últimas décadas. Desde esa óptica, el descontento de la mayor parte de la ciudadanía con los partidos tiende a relacionarse mecánicamente con el deterioro de sus niveles de 
ingresos. El error de ese tipo de reducciones explicativas consiste en convertir al interés económico en el factor clave de la producción de las subjetividades, visión de lo social, por otra parte, totalmente afín al denominado pensamiento único popularizado por el neoliberalismo.

Por el contrario, aquí entendemos que es válido relacionar la fragmentación social con lo sucedido con las creencias en la legitimidad de los partidos políticos y sus dirigentes, en la medida que consideramos que dicho debilitamiento de la cohesión social tiene como consecuencia la aparición de procesos de individualización, en el sentido que Ulrich Beck da a ese concepto, que hacen que los sujetos tiendan a tomar distancia de sus anteriores creencias y tradiciones. La gran mutación social que se registró en los recientes decenios no fue la aparición de la pobreza ni la concentración del poder económico, tampoco es nueva la heterogeneidad de los sectores medios. Lo más relevante de los cambios producidos fue la crisis de las anteriores identidades sociales, la declinación de los antiguos actores colectivos, la multiplicación de los modos de vida diferentes, la caída de muchas de las certezas precedentes.

Para decirlo de otro modo, se registraron crisis de sentido, fenómenos que aparecen en las sociedades que registran cambios sociales rápidos, ya sea que favorezcan o que perjudiquen a distintos sectores de sus poblaciones. Con la crisis de sentido aumenta la reflexión sobre lo social, y lógicamente sobre lo político, de muchas personas que antes estaban más sujetadas por las ideas hegemónicas y por los criterios de autoridad que fijaban límites a sus percepciones y a sus razonamientos. En otras palabras: el mayor éxito de la vigencia de la democracia, de la libertad de expresión, del fin del autoritarismo en los ámbitos culturales y de la comunicación, fue la aparición de múltiples y opuestos modos de pensar. Los efectos del cambio de régimen político se combinaron luego con la modernización económica que hizo más heterogénea la estructura social y, a la vez, la apertura al mundo globalizado completó la complejidad de los factores en presencia.

De todas esas contradictorias transformaciones salieron individuos más exigentes frente a las instituciones estatales y a los partidos políticos, menos proclives a acordar legitimidad a partir de criterios tradicionales o de sus afinidades políticas anteriores con sectores dirigentes y, por lo tanto, más inclinados a defender lo que consideran sus derechos de ciudadanos. Esas personas, no importa cual fue su participación porcentual sobre el total de la población, reaccionaron en esferas distintas contra los privilegios, los abusos de poder y las más disímiles formas de injusticia, más allá que se hallasen entre los ganadores o los perdedores de la esfera económica.

Si en lugar de tomar el término fragmentación como un sustantivo que describe las fisuras del mundo social se lo emplea como un concepto para hacer inteligible el debilitamiento de los vínculos sociales y sus consecuencias sobre las subjetividades, con la desorganización de las anteriores entidades colectivas, se puede establecer una referencia teórica fuerte para explicar las nuevas construcciones imaginarias de la sociedad que verbalizan los entrevistados o encuestados que dicen no tener confianza en los dirigentes partidarios. El debilitamiento de la co- 
hesión social está en la base de la mayor diferenciación individual que posibilita las evaluaciones ciudadanas más exigentes sobre el respeto de las regulaciones jurídicas y, obviamente, la percepción de las desigualdades políticas que vulneran el funcionamiento esperado del régimen democrático.

En el caso argentino, las frecuentes movilizaciones sociales de protesta ante situaciones de injusticia de los más disímiles tipos produjeron las fusiones de esas conciencias individuales en torno a los temas directamente relacionados con el cuestionamiento a la legitimidad de las instituciones públicas, de los partidos políticos y de sus dirigentes. Más allá que se tratase de incumplimientos de compromisos salariales, crímenes que se atribuían a elites provinciales, violación de regulaciones del sistema bancario, reclamos de mayor seguridad urbana, etc., la falta de idoneidad y/o las transgresiones de quienes desempeñaban funciones públicas suscitaron reacciones individuales y colectivas denunciando el incumplimiento de las leyes. Si los tejidos sociales más sólidos y la mayor integración social tienden a generar representaciones colectivas durables, con altas probabilidades de aparición de organizaciones corporativas o políticas permanentes, en cambio, con las condiciones de fragmentación social surgen conductas anómicas, generándose reacciones puntuales y erráticas, a veces violentas, que provocan un mayor debilitamiento de la legitimidad de las instituciones políticas.

En la medida que la sociedad se hace menos representable, quienes se proponen realizar procesos de agregación de las demandas dispersas se encuentran con las dificultades de hacerlas compatibles entre sí. No es sorprendente, entonces, que con el aumento de las acciones sectoriales de autorepresentación hayan declinado las creencias en la legitimidad de los partidos y del parlamento, dado que esas instancias institucionales de negociación perdieron capacidades para armonizar y articular intereses parciales a los efectos de convertirlos en intereses generales.

\section{Conclusiones abiertas}

Tal como muchos aspectos lo indican, la combinación de factores que llevaron a la pérdida de la legitimidad de las instituciones estatales y de los partidos políticos se pone de manifiesto con frecuencia en nuestros días. Esa situación de escasa legitimidad no implica un riesgo inmediato para la existencia del régimen democrático pero disminuye la calidad de la vida pública. Sin duda, no existen soluciones mágicas e inmediatas para mejorar los nexos entre la ciudadanía y el sistema representativo, pero eso no debe llevar a obviar que la reproducción de las prácticas que debilitaron la legitimidad de las instituciones estatales y de los partidos deja abierto un futuro incierto para el todavía joven régimen democrático. Es notorio que en la opinión pública no existe un cuestionamiento de la validez del orden político democrático en cuanto tal y el horizonte de referencias negativas lo siguen ocupando los dictadores militares. Las críticas a los dirigentes partidarios, las objeciones al funcionamiento de la justicia, las disconformidades con las políticas económicas, las denuncias de los numerosos casos de corrupción, las protestas ante los excesos e ineficiencias policiales, y la enumeración podría continuar, son temas que en principio preocupan a sectores distintos de la población 
que ven afectados sus intereses particulares. Es más, no sólo todos los integrantes de esos sectores no coinciden en sus apreciaciones sino que, además, en no pocos dominios las opiniones se dividen según líneas de ruptura que impiden encontrar la unidad de las visiones contradictorias que fundamentan el malestar político existente.

La novedad de diciembre de 2001 residió en la puesta en escena de una beligerante configuración de un sistema de alteridades en la que una amplia corriente de opinión coincidió en identificarse en un nosotros (el pueblo o los ciudadanos) versus ellos (la clase política). La caída de los relatos unificadores, el debilitamiento de las corporaciones profesionales, los deterioros del sistema ocupacional, la descomposición de las antiguas solidaridades, la erosión de las filiaciones institucionales, habían dado como consecuencia la vacancia política de quienes, a los tanteos, buscaban nuevas identidades. En no pocos casos, desde las ciencias sociales, el fenómeno tendió a pensarse cifrando expectativas en la eventual aparición de nuevos partidos o movimientos sociales destinados a suturar a los individuos atomizados, para convertirlos en protagonistas de procesos de recomposición progresista de la escena política primero y de la sociedad luego. Sería, entonces, resuelta una crisis que era definida, como en el caso de la salud de una persona, como una enfermedad pasajera. Siguiendo ese tipo de razonamientos no fueron pocos los que creyeron que en los sucesos de 2001 se encontraba el nacimiento de nuevas fuerzas sociales que reemplazaban a las de etapas anteriores. Desde esa óptica, la protesta de los individuos debía dar paso a la organización de sus demandas, al encuadramiento de sus preferencias, en síntesis, a la "reconstrucción de un sistema político normal para un país en serio".

Dichos observadores y narradores interesados por los fenómenos políticos de 2001 pusieron el énfasis en la irrupción en el espacio público de nuevos actores destinados a sustituir, según opinaban, a los antiguos. En el margen opuesto se situaron aquellos que leyeron los hechos desde una óptica que remitía a la simple alternancia, poco prolija por cierto, entre las dos fuerzas partidarias que se turnaban en el control de los gobiernos nacionales y provinciales desde hacía más de medio siglo. Prácticamente, todas las visiones inmediatas captaban aspectos significativos de los acontecimientos, pero a la distancia de esos sucesos cabe destacar como traza más permanente de lo ocurrido el mantenimiento de la declinación de la legitimidad los partidos políticos, así como las notorias dificultades de crear nuevos. Mientras que en el plano económico existió una recuperación exitosa, en el político se generó una cierta polarización entre los adherentes y los opositores al gobierno 2003-2007, que se restableciese un sistema de partidos capaces de representar de un modo organizado las distintas sensibilidades en las que se habían dividido las opiniones de la ciudadanía. En las elecciones presidenciales de 2007, los Frentes expresaron la adecuación de los dirigentes políticos a la pérdida de legitimidad de los partidos. Pero, igualmente, fue un modo de aceptar el hecho de que los viejos conjuntos colectivos de personas se habían debilitado y que la convocatoria de apoyos debía hacerse a los individuos más que a los sectores sociales. Hoy, cuando se usa la noción de "sector social", se está haciendo referencia a lo 
que Pierre Bourdieu (2000) denomina un sector en el papel muy distinto al que poseía los atributos de hace varias décadas atrás. Si en un plano los Frentes pusieron de manifiesto las debilidades organizativas y las divisiones de los partidos que formalmente los integraban, en otro, al juntar candidatos de las más opuestas procedencias revelaron el alto grado de licuación de las antiguas identidades. Los Frentes supusieron alteridades ocasionales a diferencia de la época de los partidos, en la que el otro era un adversario bien definido. Es interesante destacar al respecto que la idea de la volatilidad de las preferencias ciudadanas se encontró presente en las estrategias de los tres Frentes considerados con más probabilidades competitivas: todos sabían, más por sentido práctico que por lecturas de modernas teorías sociales, que los procesos de individualización habían hecho más heterogénea la sociedad y exigentes a los ciudadanos. Los viejos partidos habían sido constructores de la política sólida, en tanto que la fluidez de los Frentes era una expresión del bricolage precario de la política líquida: "hoy estamos, mañana...".

La distancia sociedad-partidos, no debe, sin embargo, confundirse con el desinterés por lo público ya que el mismo crece, normalmente, junto con la mayor información y educación ciudadana que caracteriza la época actual. Las personas que se hacen más exigentes y desconfían de muchas de las instituciones y personalidades en las que antes creían más o menos irreflexivamente, no son apolíticas. Por otra parte, si en la Argentina se mantuviese de un modo prolongado el debilitamiento de la legitimidad de fuerzas políticas sin organizaciones deliberativas y continuase la inclinación a colocar en el centro de la arena electoral a personalidades que compiten por los altos cargos de gobierno, eso crearía las condiciones típicas en las que los grandes intereses corporativos ven crecer sus capacidades de intervención en los procesos de toma de decisiones. No cabe descartar, tampoco, que la demagogia, la desviación clásica de la democracia, gane espacio en una escena política así desestructurada.

\section{Referencias}

1. La investigación se desarrolló en el marco del proyecto UBACyT: "Desestructuración de los vínculos sociales y pérdida de legitimidad de los partidos políticos argentinos y de las instituciones estatales en los 20 años de reconstrucción del régimen democrático" y de un Taller de Investigación de la Carrera de Sociología de la Facultad de Ciencias Sociales de la UBA. Se realizaron 250 entrevistas no directivas a ciudadanos argentinos residentes en la Ciudad Autónoma de Buenos Aires, siguiendo los criterios de selección y de análisis de la información que muy resumidamente se presentan en el curso del presente texto.

2. Se trata de informaciones provenientes de una encuesta multipropósito y longitudinal, con diseño en panel, aplicada a una muestra aleatoria de 2.500 casos representativos de la población de 18 años y más, residentes en el Área Metropolitana de Buenos Aires, Gran Córdoba, Gran Rosario, Gran Salta, Gran Resistencia, Gran Mendoza, Paraná, Bahía Blanca y Neuquén.

3. Al respecto ver, N. BOTANA (2006) y H. QUIROGA (2005), Cap. 8.

4. Al respecto, ver K. VON BEYME (1995), p.97.

5. $\mathrm{Al}$ respecto, ver G. ABOY CARLÉS (2001).

6. Sobre la politización de los Juicios a la Juntas, J. MALAMUD GOTI (2000:204) sostiene que: "Lo que sucedió en la Argentina es que una sociedad fragmentada no consideró -y sigue sin considerar-a los juicios como un modo de implantar el sentido de la responsabilidad personal, esencial para una democracia fundada en el respeto a los derechos individuales". Al respecto, ver S. PEREYRA (2005). 
7. Como resume Habermas (2005:535): "Max Weber entiende los órdenes estatales de las sociedades occidentales modernas como acuñaciones de la 'dominación legal'. Basan su legitimidad en la fe en la legalidad del ejercicio de la dominación. La dominación legal cobra su carácter racional entre otras cosas porque la fe en la legalidad de los órdenes establecidos y en la preparación y competencia de los llamados al ejercicio de la dominación es de calidad distinta que la fe en la tradición o el carisma: es la racionalidad inmanente a la forma jurídica misma la que procura legitimidad a la dominación ejercida en formas legales".

8. Sobre las percepciones sociales de la corrupción en Argentina, hemos consultado los Informes Latinbarómetro del período analizado.

\section{Bibliografía}

G. ABOY CARLÉS (2001), Las dos fronteras de la democracia argentina, Rosario, Homo Sapiens.

Z. BAUMAN (2003a), Modernidad líquida, Buenos Aires, Fondo de Cultura Económica. (2003b), "Individualmente, pero juntos", Prefacio de Z. Bauman a U.BECK; E. BECKGERNSHEIM, La individualización. El individualismo institucionalizado y sus consecuencias sociales $y$ políticas, Barcelona, Paidós.

N. BOTANA (2006), Poder y hegemonía. El régimen político después de la crisis, Buenos Aires, Emecé.

P. BOURDIEU (2000), “¿Cómo se hace una clase social? Sobre la existencia teórica y práctica de los grupos”, en P. BOURDIEU, Poder, derecho y clases sociales, Bilbao, Desclée.

R. CASTEL (2004), La inseguridad social. ¿Qué es estar protegido?, Buenos Aires, Manantial.

R. DAHRENDORF (1997), After 1989: Morals, Revolution and Civil Society, London, Macmillan.

A. GIDDENS (2000), Un mundo desbocado. Los efectos de la globalización en nuestras vidas, Madrid, Taurus.

J. HABERMAS (2005), Facticidad y validez. Sobre el derecho y el Estado democrático de derecho en términos de teoría del discurso, Madrid, Editorial Trotta.

J. LINZ (1978), The Breakdown of democratic regimes: Crisis, Breakdown and Reequilibration, Baltimore, John Hopkins University.

J. MALAMUD GOTI (2000), Terror y justicia en la Argentina. Responsabilidad y democracia después del terrorismo de Estado, Buenos Aires, Ediciones de la Flor.

S. PEREYRA (2005), “¿Cuál es el legado del movimiento de derechos humanos? El problema de la impunidad y el reclamo de justicia en los noventa", en F. SCHUSTER et al. (compiladores), Tomar la palabra. Estudios sobre protesta social y acción colectiva en la Argentina contemporánea, Buenos Aires, Prometeo-Facultad de Ciencias Sociales.

H. QUIROGA (2005), La Argentina en emergencia permanente, Buenos Aires, Edhasa.

R. SIDICARO (2004), "Coaliciones golpistas y dictaduras militares: el "proceso" en perspectiva comparada", en A. PUCCIARELLI (comp.), Empresarios, tecnócratas y militares. La trama corporativa de la última dictadura, Buenos Aires, Siglo XXI.

M. WEBER (1999), Economía y sociedad. Esbozo de sociología comprensiva, México, Fondo de Cultura Económica.

K. VON BEYME (1995), Las clases políticas en el Estado de los partidos, Madrid, Alianza.

Recibido: 20/09/08. Aceptado: 20/10/08 